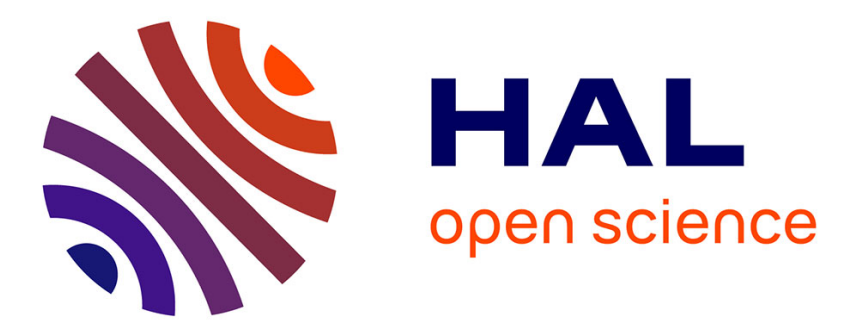

\title{
Superstitions, cultures et sports, entre croyances et rationalisations. Le cas exploratoire d'une équipe féminine professionnelle de volleyball en France
} Manon Eluère, Stéphane Héas

\section{- To cite this version:}

Manon Eluère, Stéphane Héas. Superstitions, cultures et sports, entre croyances et rationalisations. Le cas exploratoire d'une équipe féminine professionnelle de volleyball en France. Les cahiers Internationaux de Psychologie Sociale, 2017, 113 (1), pp.25. 10.3917/cips.113.0025 . hal-02171668

\section{HAL Id: hal-02171668 \\ https://hal.univ-rennes2.fr/hal-02171668}

Submitted on 9 Jul 2019

HAL is a multi-disciplinary open access archive for the deposit and dissemination of scientific research documents, whether they are published or not. The documents may come from teaching and research institutions in France or abroad, or from public or private research centers.
L'archive ouverte pluridisciplinaire HAL, est destinée au dépôt et à la diffusion de documents scientifiques de niveau recherche, publiés ou non, émanant des établissements d'enseignement et de recherche français ou étrangers, des laboratoires publics ou privés. 
SUPERSTITIONS, CULTURES ET SPORTS, ENTRE CROYANCES ET RATIONALISATIONS. LE CAS EXPLORATOIRE D’UNE ÉQUIPE FÉMININE PROFESSIONNELLE DE VOLLEYBALL EN FRANCE Manon Eluère et Stéphane Héas

Presses universitaires de Liège | « Les Cahiers Internationaux de Psychologie Sociale »

2017/1 Numéro 113 | pages 25 à 55

ISSN 0777-0707

ISBN 9782875621283

Article disponible en ligne à l'adresse :

https://www.cairn.info/revue-les-cahiers-internationaux-de-psychologiesociale-2017-1-page-25.htm

Distribution électronique Cairn.info pour Presses universitaires de Liège.

(C) Presses universitaires de Liège. Tous droits réservés pour tous pays.

La reproduction ou représentation de cet article, notamment par photocopie, n'est autorisée que dans les limites des conditions générales d'utilisation du site ou, le cas échéant, des conditions générales de la licence souscrite par votre établissement. Toute autre reproduction ou représentation, en tout ou partie, sous quelque forme et de quelque manière que ce soit, est interdite sauf accord préalable et écrit de l'éditeur, en dehors des cas prévus par la législation en vigueur en France. Il est précisé que son stockage dans une base de données est également interdit. 


\section{6 \\ Superstitions, cultures et sports, entre croyances et rationalisations. Le cas exploratoire d'une équipe féminine professionnelle de volleyball en France}

Superstitions, cultures and sports, between beliefs and rationalization. The exploratory case of a professional women volleyball team in France

Manon ELUÈRE ${ }^{1}$ et Stéphane HÉAS²

1. École Normale Supérieure de Rennes (ENS 2SEP), France

2. Laboratoire VIPS², université Rennes 2, France 
Superstitions, cultures et sports, entre croyances et rationalisations. Le cas exploratoire d'une équipe féminine professionnelle de volleyball en France

L'objectif de cette recherche est de préciser l'influence de la nationalité et plus largement de la culture au sein d'un groupe sportif, dans le recours à la superstition. Cette étude de cas analyse l'attachement à ces croyances de l'ensemble des membres d'une équipe féminine professionnelle de volleyball réunissant des joueuses de différentes nationalités. Une méthode couplant quantitatif et qualitatif (questionnaires, sociométrie et entretiens) de manière complémentaire permet de rendre compte de la complexité du phénomène superstitieux. Les résultats montrent que certaines constructions culturelles sont au centre des croyances. La socialisation primaire apparaît la plus déterminante pour ce qui est de l'adoption de rituels, à travers l'éducation familiale. In fine, trois profils superstitieux émergent en lien avec les nationalités. Mots-clefs : Superstition, croyances, groupe, culture.

Superstitions, cultures and sports, between beliefs and rationalization. The exploratory case of a professional women volleyball team in France

The purpose of this study is to clarify the respective influence of the nationality and more widely of the Culture on the recourse to superstition. It analyses the presence of superstitious beliefs within a professional female volleyball team gathering players of different nationalities. The dual use of quantitative and qualitative methods (questionnaires, sociometry and interviews) helps reveal the complexity of the superstitious phenomenon. Results show that culture is indeed at the core of superstitious practices. Primary socialization, i.e education and family's values, has a decisive influence on type of rituals used. We identify three superstitious profiles based on nationality. Key words: Superstition, beliefs, group, culture.

Aberglauben und Spitzen-Sport. Das Beispiel einer weiblichen Mannschaft professionellen Volleyballs

Der Forschungsgegenstand dieser Studie ist es, den Einfluss der Sozialisation innerhalb einer Sport-Gruppe auf ein Rekurrieren von Aberglauben herauszuarbeiten. Diese Fall-Studie analysiert das Festhalten an diesen Überzeugungen bei der Gesamtheit der Mitglieder einer weiblichen professionellen Sportgruppe bei Volleyball, die Spielerinnen unterschiedlicher Nationalitäten umfasst. Eine Methode, die quantitative und qualitative Vorgehensweisen (Fragebogen, Soziometrie und Interviews) komplementären Charakters verbindet, erlaubt es, der Komplexität des Phänomens des Aberglaubens Rechnung zu tragen. Die Ergebnisse zeigen, dass gewisse kulturelle Konstrukte im Zentrum der Überzeugungen stehen. Die primäre Sozialisation scheint im Hinblick auf die Adaptierung von Ritualen, vermittelt durch die familiäre Erziehung, die wichtigste Determinante zu sein. Letztlich zeigen sich im Zusammenhang mit den Nationalitäten drei Profiltypen des Aberglaubens.

Supersticiónes y deporte de alto nivel. El ejemplo de un equipo femenino profesional de voleibol El objetivo de esta investigación es de precisar la influencia de la socialización dentro de un grupo deportivo, en el uso de la superstición. Este estudio de caso analiza el 

La correspondance pour cet article doit être adressée à Stéphane Héas, université Rennes 2, UFR APS, avenue Charles Tillon, 35044 Rennes, France ou par courriel <stephane.heas@ univ-rennes2.fr>.

Remerciements : Nous tenons à remercier M. Joffrey Bardin pour avoir contribué au travail d'entretiens avec les joueuses. Nous remercions tout particulièrement Mlle Pauline Eluère pour son aide précieuse pour la traduction des résumés et du questionnaire de superstition. 


\section{Introduction}

Aujourd'hui, au sein des sociétés occidentales, malgré et en parallèle du développement des sciences, les superstitions, occupent une place conséquente, en témoigne prosaïquement la présence d'horoscopes dans les magazines. En 2008, un sondage TNS indiquait que 41\% des Français se déclaraient superstitieux, et selon un autre procédé de sondage, $23 \%$ en $2014^{1}$. Des pratiques superstitieuses comme le trèfle à quatre feuilles porte bonheur par exemple concernent toujours presque la moitié de la population française. Les sondages indiquent de fortes variations entre les pays d'Europe et suivant les questions posées. Les superstitions semblent perdurer et se maintenir à travers des conduites plus ou moins stéréotypées. Ainsi, les rituels, sacrés ou profanes, échappant à toute logique rationnelle et/ou scientifique remplissent toujours des fonctions importantes au sein des sociétés contemporaines (Maranise, Michael, 2013). Ils permettent de faire face à des situations incertaines, voire risquées, de diminuer le niveau d'anxiété des pratiquants, de mieux maîtriser des situations vécues comme incontrôlables (Gollier, 2005). Or, les sports constituent par définition des situations incertaines où le contrôle de soi est important sous peine d'échec, individuel ou collectif. En outre, la naissance historique des sports modernes en Angleterre et leur développement à la fin du XIXème siècle en Europe et aux Etats-Unis ne sont pas des processus dénués d'influence religieuse (les religions catholiques et protestantes ont participé à ce développement, directement ou non). Depuis, I'importance de la religion ne s'est probablement pas amoindrie sur les terrains sportifs (Aitken, 1993 ; Higgs, 2015). Surtout, les sports sont aussi largement considérés comme des espaces où prolifèrent les superstitions, particulièrement dans les sports professionnels et collectifs, même si les attitudes et les actes superstitieux sont observés quelle que soit la pratique sportive (Gay, 1990 ; Vyse, 2013). Notre recherche originale interroge une pratique sportive de haut niveau où l'entraînement le plus rationnel côtoie des comportements superstitieux et religieux. Les notions de rationalité/ irrationalité et les fonctions que remplissent les phénomènes superstitieux interpellent. L'approche psychosociologique choisie cherche à montrer à partir d'une étude de cas circonscrite l'influence de la socialisation et de la culture sur le type de rituels adoptés et les recours à la superstition pour performer.

\subsection{Croyances superstitieuses, croyances religieuses et rationalités contemporaines}

Les distinctions entre les différentes formes de rationalité et d'irrationalité participent de modes de classement spécifiques à chaque culture : «Est-ce à dire que la notion de "logique » ne puisse à elle seule garantir rigoureusement la démarcation entre le rationnel et ce qui n'est pas lui ? »(Bonardel, 2005, 6). Selon Tremblay cette popularité croissante des pratiques irrationnelles s'explique par la crise que traversent les sociétés modernes contemporaines (2000). Les croyances et notamment les superstitions interviennent en réponse à des situations hors de contrôle et s'imposent finalement comme des recours logiques...aux yeux des acteurs. L'adoption consciente de croyances permet de composer avec l'incertain, si ce n'est de vaincre l'incertitude de la situation. L'étymologie du mot superstition 
réfère à la protection : " voir au-delà pour s'attirer la protection des dieux » (Lapointe, 2000, 6). Ces croyances, qu'elles soient superstitieuses ou religieuses, se traduisent par des actions répétées, souvent ritualisées. Cependant, plus que la superstition, la religion réfère à une institution, i.e. à une organisation spécifique et légitime autour de croyances. De plus, les croyants au sens religieux du terme sont convaincus de l'efficacité et de l'importance de leurs rituels à plus ou moins long terme (prières, messes etc.) tandis que la grande majorité des personnes ayant recours à des comportements superstitieux « reconnaissent ces actions comme inefficaces » per se (Bleak, Frederick, 1998). Elles ont pleinement conscience du caractère irrationnel de leurs comportements (Risen, Gilovich, 2007)². D'ailleurs, la superstition apparaît particulièrement dans les activités plus ou moins liées à la chance (Torgler, 2007) ou celles dans lesquelles le risque professionnel est présent (Askevis-Leherpeux, 1990).

Malgré une frontière qui peut parfois sembler floue entre superstition et religion, ces deux croyances sont distinctes et il convient d'ailleurs d'effectuer cette distinction ; ce que nous nous attacherons à faire dans cette étude. Il semble toutefois nécessaire de ne pas ignorer les croyances religieuses lorsque l'on étudie les superstitions et rituels puisque certaines études ont d'ores et déjà mis en évidence que les variables religieuses sont déterminantes pour comprendre les croyances paranormales (e.g. Orenstein, 2002 ; Rice, 2003). Plus encore, "les sciences humaines mettent en lumière la coexistence habituelle de la magie ${ }^{3}$ et de la religion. Tantôt en concurrence, tantôt en compromis, elles sont mêlées l'une à l'autre (...) De plus, on peut noter parfois la contagion de l'une sur l'autre» (Tremblay, 2000).

\subsection{Sports et superstitions}

L'environnement sportif apparaît propice à l'émergence de comportements superstitieux (Womack, 1992) : la chance est susceptible d'intervenir et les conditions sont incertaines, anxiogènes, voire risquées (Bleak, Frederick, 1998). Selon Dugas et al. (2013) les sports font partie du « domaine de l'incertain (comme des) espaces qui augurent d'une montée en puissance de l'aléa, de l'imprévisibilité » (p. 8), et plus l'incertitude croît plus les comportements superstitieux sont sollicités (Brevers et al., 2011). La littérature, principalement anglo-saxonne, fait état d'une vingtaine d'études à propos de la superstition en lien avec le sport, depuis le début des années 1980. Les comportements superstitieux y sont définis comme " des actions répétitives, formelles, séquentielles et distinctes de la performance technique, que les athlètes croient puissantes pour contrôler la chance et d'autres facteurs externes »(Bleak, Frederick, 1998, 1). Schippers et Van Lange ${ }^{4}$ (2006) évoquent " un comportement insolite, répétitif et rigide » dont l'individu perçoit des effets positifs. D'ailleurs, les effets semblent réellement positifs en améliorant la confiance, voire l'estime de soi du sportif (Damish et al., 2010). Le sexe des pratiquants intervient, les femmes semblant particulièrement enclines à engager des actes superstitieux (Buhrmann et Zaugg, 1981).

Puisqu'ici nous étudions ce phénomène ancré dans l'environnement sportif, il est nécessaire de différencier la superstition des "routines de pré-performances ", 
développées par les experts, qui représentent des « comportements appris et stratégies cognitives utilisées intentionnellement par les sportifs pour faciliter la performance »(Cohn, 1990) $)^{5}$. Contrairement aux rituels superstitieux, les "routines » ne sont pas utilisées à toutes les échelles de la compétition, mais principalement dans la phase préliminaire, dite de "pre game ». Elles aident à préparer les sportifs en complétant une série de compétences automatiques malgré les variations du contexte sportif (McCann, 2008 ; Taylor, 2012 ; Wrisberg and Pein, 1992) ${ }^{6}$. Ainsi, les routines permettent d'être « physiquement, techniquement, tactiquement et mentalement prêt à performer » (Billing, 2014, 10) et se différencient donc des rituels de superstition puisqu'ils détiennent un aspect technique, physique et surtout rationnel.

La superstition semble être un objet pluriel à manipuler avec précautions pour éviter les confusions avec certaines pratiques et croyances. Ainsi, les travaux rapportés par la littérature s'attachent à décrire les superstitions et leurs déterminants, mettant en évidence différentes fonctions des superstitions chez les sportifs (Goodall, 2010) ou des facteurs favorisant l'apparition de rituels superstitieux (le niveau de pratique, le sexe, l'âge, l'anxiété, la classe sociale, etc.). Toutefois, malgré la complexité apparente du phénomène étudié, les travaux portant sur la superstition utilisent quasiment exclusivement des méthodes quantitatives par questionnaires. Par ailleurs, Askevis-Leherpeux (1978) remarquait, à l'époque, qu'une grande partie des travaux portant sur la superstition sont anglo-saxons et sont réalisés sur la base d'un même paradigme consistant à demander aux sujets de "se prononcer sur une liste d'énoncés considérés arbitrairement par l'auteur comme relevant de la superstition ». Cependant, "les auteurs s'intéressent à des croyances superstitieuses sans jamais définir avec soin leur champ d'étude ni par rapport à la science ni par rapport à la religion» (p. 165). La méthode retenue pour cette recherche se veut donc à la fois quantitative et qualitative pour pouvoir rendre compte de la complexité de l'objet d'étude que représente la superstition.

\subsection{Culture et superstitions}

Les actes superstitieux font partie d'une pratique largement acceptée et utilisée par les athlètes à travers différentes cultures (Womack, 1992). Cependant, et de manière surprenante, comme le souligne Torgler, il existe un manque de preuves empiriques à propos de ce qui façonne les superstitions des individus (2007). Certaines études se sont attachées à comparer des individus de différents pays, mettant notamment en évidence que les pays anciennement communistes présentent un degré de superstition statistiquement plus élevé que les autres pays (Torgler, 2007) ou encore que des joueurs de baseball japonais ont moins tendance à engager des comportements superstitieux comparé à des joueurs de baseball américains (Burger \& Lynn, 2005). Il semble donc que la nationalité, et peut-être plus largement la culture, influencent le rapport entretenu par les individus à la superstition et le type de rituels dans lesquels ils s'engagent. Dans une récente étude, Obadia semble confirmer cette idée, soulignant le fait que les rituels sont " géographiquement dispersés et culturellement distribués 》(Obadia, 2016, 2). 
Les définitions de la culture sont nombreuses mais nous retiendrons ici celle de Rocher puisque tout comme "I'objet superstition" elle se situe au croisement de diverses disciplines scientifiques (i.e., anthropologie, sociologie). Ainsi, "la culture est un ensemble lié de manière de penser, de sentir, d'agir, plus ou moins formalisé qui étant apprise et partagée par une pluralité de personnes servent d'une manière à la fois objective et symbolique à constituer ces personnes en une collectivité particulière et distincte" (Rocher, 1992, 15). Lorsque l'on évoque la culture on sous-entend des traits communs à une société, à un groupe d'individus, à une nationalité. Ce sont ces tendances homogènes qui nous intéressent dans cette étude, bien que tous les individus soient pluriels puisque traversés par diverses cultures (Lahire, 2004). C'est d'ailleurs pourquoi les notions de socialisation primaire et secondaire, que Berger et Luckmann mettent en tension dans leur théorie (Berger et Luckmann, 2002) sont nécessaires pour "segmenter" en quelque sorte les influences d'une culture individuelle. D'ailleurs, "une telle conceptualisation intéresse la psychologie, dans la mesure où elle contribue, de manière originale, à introduire la dimension sociale et culturelle comme une matrice dans laquelle se construit l'organisation psychologique" (Qribi, 2010, 133).

\section{Objectif de l'étude et hypothèses}

Nous avons spécifiquement tenté de mettre en évidence l'influence de la culture sur le rapport entretenu avec la superstition, dans le monde sportif, milieu dans lequel les rituels sont particulièrement prégnants. Au-delà du calcul d'un « taux de superstition ", ce sont bien les types de rituels employés et la posture individuelle à l'égard de ces rituels que nous pensons être révélateurs d'un mode de fonctionnement humain, ici sportif. Nous nous sommes attachés à comprendre les déterminants psychologiques des rituels superstitieux, considérant la superstition comme un acte culturel à envisager aux côtés des croyances au sens général du terme ${ }^{7}$. Les superstitions participent à la réduction de l'incertitude (voire des risques de blessure, de défaite, etc.) liée à la situation sportive en même temps qu'elles permettent un contrôle émotionnel des sportifs, et donc in fine un contrôle de soi (Gollier, 2005). Ainsi, prenant en compte religions, valeurs, rituels et superstitions, l'objectif de cette étude est de déterminer l'influence de la socialisation primaire et secondaire des joueuses sur leurs comportements superstitieux. Soit, de préciser leur posture superstitieuse au regard notamment de leur background culturel (au niveau national, voire régional), de leur éducation mais aussi de leur socialisation au sein du groupe sportif à travers la cohésion, les normes de l'équipe et le poids éventuel du leader. L'intérêt de cette approche est d'aborder cette question à partir des trajectoires des joueuses telles qu'elles peuvent les relater a posteriori ${ }^{8}$.

Hypothèse 1 : la nationalité (1.1) et l'éducation primaire (1.2) des joueuses influenceraient l'adhésion superstitieuse et le type de rituels adoptés. Dès lors, il serait possible d'observer différents sous-groupes selon les nationalités partageant de manière implicite ou explicite des comportements superstitieux, qui sans être exclusifs d'une culture peuvent être particulièrement valorisées en son sein. 
Hypothèse 2 : certains rituels apparaîtraient au gré des phénomènes de dynamique du groupe sportif, par conséquent en soulignant l'importance du contexte et de la situation sportive, au gré des interactions. Les superstitions seraient alors partagées en lien avec la cohésion ou bien imposées par les normes du groupe (2.1) et/ou à partir de l'influence $d^{\prime}$ 'un, en l'occurrence $d^{\prime}$ une leader (2.2). Ainsi, les joueuses avec des affinités sur le terrain ou en dehors seraient susceptibles de partager des superstitions communes, tandis que certaines joueuses auraient recours à la superstition par conformisme.

\section{Méthode}

Le terrain d'étude est constitué d'une équipe féminine professionnelle de volleyball évoluant en Ligue A féminine (LAF) pour la saison 2014-2015. Cette équipe a été entièrement remaniée pour leur montée en LAF (en 2014) avec neuf joueuses sur dix nouvellement intégrées à l'effectif. Les joueuses sont issues de cultures différentes : trois Françaises, quatre Américaines, une Brésilienne et deux Est-Européennes. Dans un premier temps nous avons eu recours à une méthode exploratoire par questionnaire, optant pour la version adaptée par Flanagan (2013) du Questionnaire des rituels superstitieux de Bleak et Frederick (1998). L'analyse qualitative par entretiens $(n=6)$ se focalisant sur certaines pratiquantes en fonction des résultats au questionnaire de superstition mais aussi par rapport à leurs statuts au sein du groupe, obtenus, lui, par un travail de sociométrie appliquée à cette équipe.

\subsection{Le questionnaire des rituels superstitieux}

Le questionnaire des rituels superstitieux de Bleak et Frederick modifié par Flanagan est organisé en sept sections qui correspondent à des catégories spécifiques de comportements superstitieux : "Vêtements et apparence », "Porte bonheur ", "Préparation », " Match », "Compétition », "Rituels d'équipe », "Prière », "Coach ». Cette version du questionnaire propose en plus onze questions dans une deuxième partie intitulée "Rituels de superstition ». Une question ouverte a aussi été ajoutée, proposant aux enquêtés de mentionner tous types de rituels employés qui ne seraient pas présents dans le questionnaire. Cette version semblait donc particulièrement intéressante pour notre démarche de recherche. Par ailleurs, le score total de superstition est déterminé par la mise en lien à la fois du nombre et de la fréquence d'utilisation des rituels (mesurée par une échelle de Likert à cinq niveaux ; de "Jamais » à "Tout le temps»). Pour calculer le taux de superstition des joueuses, nous avons eu recours à un système de tableur dans lequel, les 46 questions étaient recensées et classées par catégories. Les réponses aux questions étaient comptabilisées de 0 à 4 " points », avec 4 la valeur maximale correspondant à la fréquence du recours au rituel la plus élevée ( "Tout le temps»). Le taux de superstition était donc reporté sur 184 points. 


\subsection{Le questionnaire de sociométrie}

Le questionnaire de sociométrie a été élaboré à partir de la méthode de sociométrie de Moreno ${ }^{9}$. L'objectif est donc d'étudier les "réseaux » interpersonnels et ce " test sociométrique " permet de révéler les courants affectifs préférentiels dont les directions et les intensités déterminent la structure des groupes et les destinées individuelles. Pour notre étude, l'objectif à travers la sociométrie était de déterminer le leader du groupe, les joueuses populaires, isolées voire exclues ainsi que les " clans» (sous-groupes). Pour ce faire, notre questionnaire comporte douze questions dont la moitié se rapporte à la cohésion sociale et l'autre moitié à la cohésion opératoire.

\subsection{Les entretiens}

Nous avons interviewé six joueuses (trois Françaises, deux Américaines et une Brésilienne) dont la capitaine, une joueuse leader, une joueuse isolée et une joueuse rejetée par une partie du groupe. Par ailleurs, 5 de ces 6 joueuses présentaient un taux de superstition supérieur ou égal à la moyenne de l'équipe. Nous avons choisi pour cette étude de mener des entretiens semi directifs en nous appuyant sur un guide d'entretien composé de quatre champs principaux de questionnements, pour lesquels les interventions de l'expérimentateur étaient ensuite déterminées par les réponses de l'enquêté. Nous avons aussi fait le choix d'élaborer trois questions structurantes de l'entretien proposées de manière systématique. Chaque champ de questionnement abordé avec les joueuses était agrémenté de liens avec les résultats au Questionnaire de superstition. Cela permettait des relances mettant en lien l'explicitation d'un comportement superstitieux avec un thème spécifique (socialisation primaire, secondaire etc.), permettant alors l'introduction de l'aspect culturel dans l'explication des phénomènes de superstition. Le premier champ de questions était relatif à la présentation de la joueuse d'une manière générale (nationalité, carrière de volleyeuse, âge, implication des parents dans la pratique du volley etc.). L'objectif était à la fois d'établir le contact mais aussi d'aborder la question de culture nationale, voire régionale, et de l'intégration en France et plus particulièrement dans la région de leur club. Le deuxième champ de questionnement portait directement sur le rapport de la joueuse à la superstition («Peux-tu me parler de la superstition ? De la place qu'elle occupe dans ta vie ? Ce que ça représente pour toi ?»). Puis les relances avaient pour but d'amener l'enquêtée à expliciter ses rituels et à donner son avis, notamment sur le caractère rationnel ou non de la superstition. Les relances devaient également permettre d'amener la joueuse à évoquer ses rituels ancrés dans le contexte du groupe (rituels connus, partagés, effets de la socialisation dans le groupe sur les comportements superstitieux, etc.). Le troisième champ de questionnement portait sur " la socialisation primaire ». L'objectif ici était de mieux connaître le poids potentiel de la culture sur le recours à la superstition ( "J'aimerais que tu me parles de ta famille. Est-ce que les croyances y tiennent une place particulière ? »). L'emploi du mot " croyance » a ici pour objectif de ne pas réduire les réponses de l'enquêtée aux représentations qu'elle a de la superstition en tant que croyance spécifique. Dès 
lors, les relances portaient sur les superstitions, les valeurs familiales ou encore les pratiques culturelles (notamment intéressant pour les joueuses étrangères). Cette thématique introduisait le dernier champ. Ce quatrième champ de questionnement se rapportait à la religion, la place que cette croyance occupe dans la vie de la joueuse et aux côtés de la superstition (" Peux-tu m’expliquer la différence que tu fais entre la superstition et la religion? Qu'est-ce que ça représente pour toi ?»). Le but de cette ultime thématique était, notamment à travers les relances, de distinguer l'emprise des croyances sur la joueuse en tant que pratique incorporée. Après avoir retranscrit les entretiens, nous avons sélectionné les informations à travers les thèmes qui constituent les objectifs et hypothèses de l'étude. Cette " analyse thématique » (Blanchet et Gotman, 2014, 96-98) permet de trouver une cohérence thématique inter-entretiens, favorisant la mise en relation des différents modes d'organisation individuels des joueuses à l'égard des croyances. À travers cette méthode, nous avons tenté de mettre en exergue des systèmes de croyances et de valeurs partagés selon les cultures nationales ou selon la structure du groupe. Pour cela, nous avons élaboré une grille d'analyse autour de sept thématiques principales décomposées en différentes sous catégories qui se sont logiquement imposées au fil des entretiens, semblant faire le lien entre les différents discours. De plus, nous avons effectué une analyse par mots clés, notamment pour mettre en évidence la posture des joueuses par rapport à la superstition de manière plus ou moins consciente, nous intéressant aux différents termes employés pour évoquer la superstition ou pour s'y opposer : " superstition », " rituels », " routines » et " habitudes ». Nous avons aussi porté un intérêt particulier aux termes renvoyant à l'obligation, à la rigidité à l'égard d'un rituel, permettant de mettre évidence le caractère superstitieux des pratiques à travers une certaine forme de dépendance.

\section{Résultats}

\subsection{Sociométrie}

Les résultats des questionnaires de sociométrie ont été envisagés, dans notre étude, comme pré-enquête (un des éléments orientant le choix des joueuses avec lesquelles s'entretenir). Ainsi, selon le nombre de choix (positifs ou négatifs) orientés vers certaines joueuses et l'analyse des sociogrammes notre intérêt s'est porté vers des joueuses en particulier. Nous avons notamment décidé d'interviewer Louanne du fait de son statut de capitaine ("cheffe formelle »), associé au leadership puissant mis en exergue par les résultats de la sociométrie. De ce fait, elle semblait potentiellement présenter une influence sur le groupe concernant les rituels superstitieux à adopter. Par ailleurs, ces résultats nous ont amené à choisir Adriana, Katherine et Brianna pour les entretiens, étant respectivement des joueuses "leader populaire »(Adriana), " rejetée » (Katherine) et « isolée » (Brianna) par rapport à une partie ou à la totalité du groupe. La sociométrie a également mis en évidence des " chaînes » qui constituent des sous-groupes et des dyades. Nous avons constaté de manière très nette que l'équipe est scindée en deux sous-groupes : I'un constitué par les quatre Américaines et l'autre par le reste du groupe. Ces aspects de la dynamique de groupe de cette équipe, présentés sur les Figures 1 et 2 
Figure 1 : Sociogramme de la cohésion sociale (attraction)
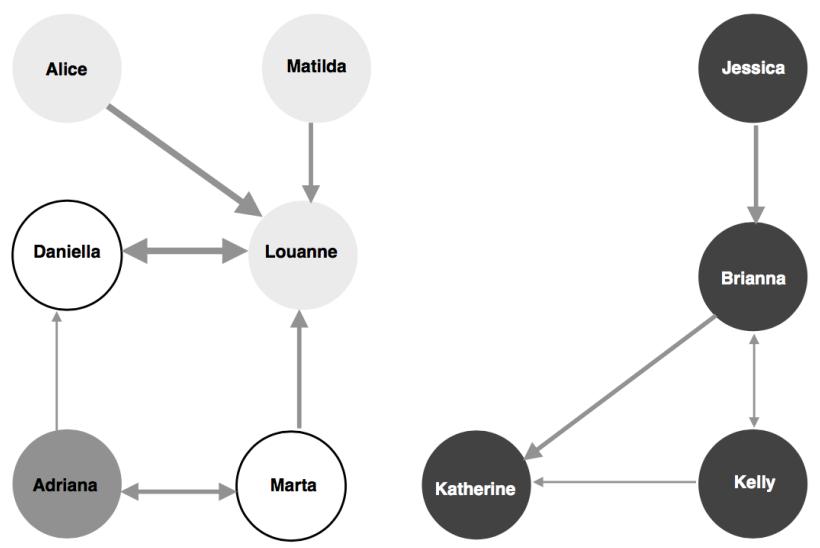

Figure 2 : Sociogramme de la cohésion opératoire (attraction)
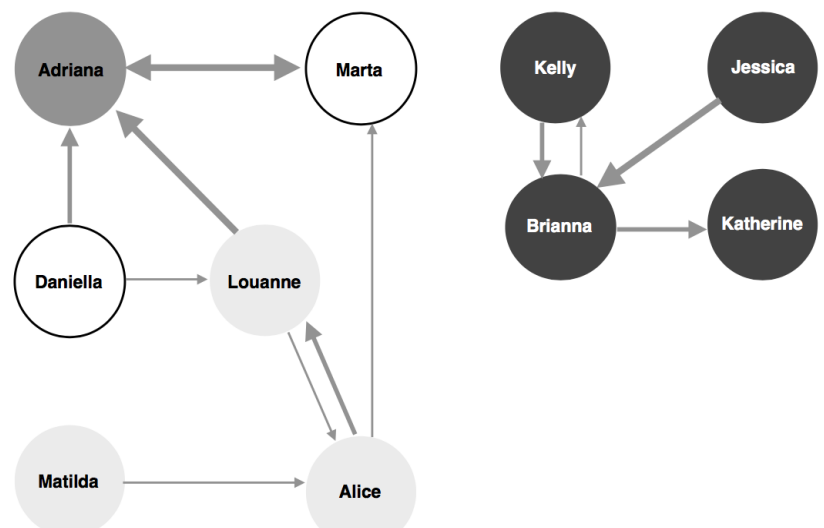

Code couleur des nationalités :

Flèches :
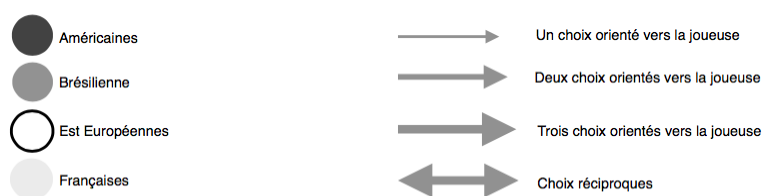

Françaises 
se sont révélés intéressants au moment de la mise en lien avec les types de rituels partagés au sein du groupe.

\subsection{Questionnaire des rituels superstitieux}

Toutes les joueuses de l'équipe $(n=10)$ ont complété le questionnaire des rituels superstitieux avec un score de superstition moyen de 67,1 sur 184 . De plus, $40 \%$ des participantes ont mentionné dans la question ouverte, un rituel ou plus, auxquels elles ont recours avant ou pendant un match. Les types de rituels mentionnés varient de l'action de " dire merci aux ramasseurs de balle avant de servir » à " ne pas vouloir uriner avant le match ». Certaines joueuses ont mentionné des rituels particulièrement intéressants tels que ne pas nouer ses lacets avant que le coach n'ait fini de parler, ne pas parler du match avant le match ou encore toujours poser le pied droit en premier dans le gymnase. Les résultats du questionnaire de superstition indiquent que la joueuse brésilienne semble être la plus superstitieuse, suivie des Françaises $(n=3)$, des Est-Européennes $(n=2)$ et enfin des Américaines $(n=4)$. Toutefois, les résultats montrent que ce sont deux Américaines qui détiennent les scores de superstition les plus extrêmes. Kelly présente un score de 42 tandis que celui de Brianna s'élève à 93. Pour autant, ces deux joueuses présentent un même niveau de croyance dans l'efficacité de leurs rituels (à quel point elles pensent que leurs rituels ont un effet sur leurs performances). Par ailleurs, nous constatons que certaines joueuses, à l'image de Louanne et Jessica, ont mentionné plus d'un rituel dans la question ouverte. Cela suppose que leur score de superstition est probablement sous-estimé par le questionnaire. Nous avons recensé 12 rituels qui sont utilisés par 7 à 10 joueuses de l'équipe : le fait de " taper dans la main des coéquipières avant et pendant le match », le fait d'effectuer un " cri de guerre avant le match » ou encore le fait " d'occuper toujours la même place dans le vestiaire ». Nous avons constaté que les rituels les plus récurrents au sein de l'équipe sont issus principalement de 4 sections du questionnaire : "Vêtements et apparence ", «Rituels d'Équipe », «Préparation » et « Match ».

\subsection{Les entretiens}

Les entretiens ont été menés avec six joueuses de l'équipe : Louanne, Matilda et Alice (des joueuses françaises), Brianna et Katherine (des joueuses américaines) et Adriana (une joueuse brésilienne) et ont duré entre 48 minutes et $1 \mathrm{~h} 09$.

Les deux joueuses américaines interviewées affirment ne pas croire en la chance mais en leur "volonté de travail" (dixit). Elles adoptent une posture distante à l'égard de la superstition dont elles se dédouanent continuellement dans leurs discours, préférant parler de "religion » et de " routines » pour rationaliser/ légitimer leurs pratiques. Bien que ces joueuses présentent deux scores extrêmes du questionnaire de superstition, elles se définissent comme des personnes "routinières ». Ainsi, lors des entretiens elles s'attachent à adopter une posture distante à l'égard de la superstition. Brianna explique : "Hum... I'm not very, like really superstitious. There is like a few things... I think that... I don't even know if it would be superstition or if it's just "routine". Hum, but yeah... I don't know (Laughter) »"10. Pourtant, cette 
joueuse révèle qu'elle porte toujours le même bandeau noir et des chaussettes spécifiques pour ses matchs. Elle enfile son équipement dans un ordre spécifique : "Yeah, I've got always like to put on my right sock first and then my left sock and then my right kneepad and my left kneepad and then my right shoes and then my left shoes ${ }^{11}$ et elle doit toujours lacer ses chaussures avec des doubles nœuds. Tous ces rituels qu'elle considère comme faisant partie d'une routine semblent tout de même relever d'une superstition, en témoigne la récurrence des termes se rapportant à l'obligation lors de l'entretien (elle emploie plus de 12 fois l'expression " have to », synonyme de " devoir »). De plus, bien qu'elle affirme ne pas être réellement dépendante de ses "routines", elle avoue avoir essayé un autre bandeau pour un match qui s'est soldé par une défaite et qui de ce fait l'a poussée à ne jamais le reporter.

Katherine semble adopter la même posture que Brianna à l'égard de la superstition, ayant particulièrement recours à des routines plus qu'à des rituels superstitieux. Cela semble cohérent par rapport à son score de superstition ; le deuxième plus faible de l'équipe. Tout comme Brianna, lorsque la thématique superstitieuse est abordée, Katherine se dédouane du recours aux rituels, mettant en évidence que de nombreux athlètes ont recours à la superstition mais qu'elle n'en fait pas partie. "I've heard about, like I know people who are very superstitious hum my brother I think he's probably more ... pretty superstitious (...) Hum... but for me hum... I don't think that I have to... like if I don't touch your right arm before I play (Elle touche mon bras) then I'm gonna play bad. (...) I more believe in like my confidence and my ability to play. So, I have like routines, I love routines. Hum... but it's not like "Ooh I didn't do that today so like every think is ruined "12. Pour ces joueuses, c'est donc "I'Autre" qui semble être superstitieux plutôt qu'elles-mêmes.

Ainsi, ces deux joueuses entretiennent une relation particulière avec les routines et cela dépasse le monde sportif. II apparaît à travers l'analyse des entretiens que les routines tiennent une place centrale dans la vie quotidienne des joueuses et dans leur famille. Brianna explique : "I think routine is the health (...) I think having a ritual... (...) Well I think like when you have kids it's important for them, like, to have like a routine every morning just so they can, we can all be on the same page. So I think it's important ${ }^{13}$. Cette place centrale accordée aux routines, notamment pour l'éducation familiale, est partagée par Katherine qui explique que les routines faisaient déjà partie de sa vie lorsqu'elle était petite ; "Hum... I think when I was a young girl (...) I think my parents kind of started that... like "Kate, if you're eating well you're gonna feel better and you're gonna have more energy for the game (...) So I think but now than I'm older and now that is kind of impregnated it's more much culture ${ }^{14}$. Ainsi, les rituels des deux Américaines semblent être en partie le résultat d'une éducation spécifique et de valeurs transmises par la famille (Brianna en parlant de sa mère : "She's really like "we have to have a routine", all the rituals like "you have to do all this stuff". Yeah she's very ... I think that's why I am ${ }^{15}$ ). II semble aussi qu'il y ait une part d'imprégnation de la culture nationale américaine au vu de la similitude des pratiques de ces deux joueuses. Par ailleurs, bien que ces deux joueuses ne présentent pas le même profil superstitieux (Brianna semble être 
une personne " routinière à caractère superstitieux » tandis que Katherine semble principalement user de routines de pré-performance), il apparaît qu'elles adoptent la même posture à l'égard de la superstition malgré un discours différent. En effet, lorsque la question de la fonction des rituels (" plutôt pour éviter le malheur ou pour favoriser la chance ») leur est posée, leurs réponses diffèrent mais détiennent le même sens. Brianna explique qu'elle a plutôt recours à ses rituels pour éviter le malheur qu'apporter la chance puisqu'elle $n^{\prime} y$ croit pas, tandis que Katherine évoque la chance au sens des « bonnes ondes » puisqu'elle non plus ne croit pas à la chance ("I think it's more to like, bring good luck. Like it's more to bring like good vibes or good like I don't think it's necessarily avoiding the other ${ }^{16}$ ). Ces deux joueuses adoptent donc des attitudes et des postures à l'égard de la superstition relativement similaires, qui semblent être le résultat de leur éducation primaire. D'ailleurs, Katherine et Brianna se définissent comme croyantes. Toutes deux vont régulièrement à l'église lorsqu'elles sont aux Etats-Unis et prient avant chaque match. Il est intéressant de noter qu'elles positionnent la religion au-dessus voire en opposition avec la superstition. Elles adoptent un point de vue similaire à ce sujet. Brianna mentionne : "I think I'm more on, like the religion side. Like, I pray before matches (...) and I think I believe more in that than I do in superstition ${ }^{17}$. Katherine formule une idée semblable : «but we are, we all raised Christian in the church so hum I think we believe more in god than we do in luck or superstition $»^{18}$.

En résumé, Brianna et Katherine accordent une place importante à la religion, au travail, aux habiletés et aux routines mais ne croient pas à la chance. Dès lors, bien que Brianna semble pencher du côté de la superstition du fait de sa "dépendance" à l'égard des routines, il semble que la culture nationale que ces deux joueuses partagent soit à l'origine de ce système de croyances commun. À les entendre, les routines tiennent une place conséquente dans le mode de vie américain. Par ailleurs, le système sportif universitaire américain est extrêmement différent de celui que nous connaissons en France et il semble que l'impact des coachs sur leurs joueuses soit particulièrement notable.

La joueuse brésilienne assume quant à elle tous les types de rituels auxquels elle a recours, l'important étant le fait de " croire », central dans sa culture et tout particulièrement dans sa famille. Lors de l'entretien, elle évoque de nombreux rituels dans lesquels elle croit profondément. Elle met « de la couleur » sur ses ongles, couleur qu'elle conservera pour le prochain match en cas de victoire. Elle se coiffe toujours de la même manière en se lissant les cheveux et en y plaçant un certain nombre de barrettes et un bandeau blanc, elle strappe ses doigts de manière symétrique, elle pose le pied droit en premier dans le gymnase et elle doit renouveler chaque saison une brassière, un string et des chaussettes qu'elle portera uniquement pour ses matchs. Par ailleurs, la couleur rouge est particulièrement importante pour elle ; "j'aime bien porter le rouge parce que le rouge pour moi il porte bonheur, la chance tu vois ». Elle explique que quand elle était petite et avait des crises de hoquet, sa mère lui donnait un fil de couture rouge qu'Adriana devait rouler entre ses doigts pour ensuite poser la boule de fil sur son front, pour faire passer la crise. Certains rituels qu'elle adopte semblent donc être le fruit de 
son éducation, de sa socialisation primaire. D'ailleurs, Adriana écoute toujours de la musique brésilienne (Samba et Gospel brésilien) avant ses matchs pour lui rappeler son pays. Ces musiques sont souvent à caractère religieux, et durant I'entretien Adriana fait naturellement le lien entre superstition et religion quand on lui demande son avis sur la superstition ; "Moi je crois, moi je crois, je ... je crois. Parce que après je suis quelqu'un aussi qui est catholique » (elle montre la croix qu'elle a autour du cou). Elle effectue toujours une "petite prière » avant les matchs pour elle et pour son équipe et elle fait le signe de croix lorsqu'elle entre sur le terrain. La religion occupe une place extrêmement importante dans sa vie, elle a donc du mal à comprendre son coach : "Oui parce que lui il croit rien, c'est bizarre ! ». Adriana est très croyante, mais on décèle dans son discours que son rapport à la religion dans le contexte sportif devient superstitieux. En effet, elle fait référence à une certaine obligation par rapport à cette prière d'avant match, qui témoigne du caractère superstitieux du rituel : "Oui faut que je fasse cette petite prière parce que sinon... ». Elle évoque aussi la place de la prière au sein des équipes brésiliennes dans lesquelles elle a évolué : " $C^{\prime}$ est bien parce que moi j'ai toujours fait au Brésil avant les matchs dans les vestiaires. Je crois même toutes les équipes on fait des prières, on $s^{\prime}$ embrasse et on fait des... une prière : le Padre Nostrum ». Encore une fois, il semble qu'une partie au moins de ses rituels soit imprégnée de sa culture nationale et de son éducation.

En résumé, les rituels d'Adriana sont très variés et imprégnés de la culture brésilienne mais aussi des valeurs et des croyances transmises par sa mère. Elle accorde beaucoup d'importance à la famille et elle explique avoir plusieurs " mamans » de substitution en France, dans les villes des clubs où elle est passée. Adriana est une joueuse qui assume son recours à la superstition en I'associant à sa foi en dieu. Une analyse par mots clés révèle qu'elle emploie plus régulièrement les mots «superstition » et « rituels » que le mot « habitude » tandis qu'elle ne parle jamais de « routines».

Enfin, les trois joueuses françaises valorisent les « énergies », les « forces », accordant un crédit particulier à la chance. Evoquer la superstition produit un véritable conflit interne chez elles : les rituels étant contraires à leur logique tout en faisant figure de pratiques irrépressibles. Les entretiens mettent en évidence la forte influence de la famille et de la socialisation primaire sur la pratique sportive des trois joueuses françaises. Notons toutefois que sur ces trois joueuses, deux d'entre elles, Alice et Matilda, sont originaires d'Europe de l'Est. Elles constituent la première génération née en France de leur famille. Elles sont donc Françaises et ont grandi à travers cette culture. Dès lors, la socialisation primaire de ces deux joueuses a été marquée par cette culture balkanique, associée à la culture française autour de laquelle elles se sont principalement construites (à travers l'école notamment). Ainsi, la double socialisation primaire que présentent Alice et Matilda constitue un point intéressant que nous ne pouvons ignorer lors de nos interprétations. Par ailleurs, il apparaît que les rituels adoptés par Alice, Louanne et Matilda sont le résultat d'une culture superstitieuse transmise par leurs parents. Alice explique que ses deux parents sont très superstitieux, confiant que son père conservait le même sous-vêtement pour 
tous ses matchs et explique : «Depuis toute petite, je ... je... enfin c'est pas que j'ai baigné dans la superstition (rires), mais ouais dès qu'il y avait un chat noir ma mère se retournait, donc du coup je faisais pareil. Oui effectivement je pense que j'ai accepté l'idée de la superstition assez (...) ma mère est très superstitieuse, enfin les "Européens de l'Est " ${ }^{19}$ en général sont superstitieux, même les jeunes ». Louanne quant à elle nous livre une devise familiale à laquelle elle tient : " une pie tant pis, deux pies tant mieux, trois pies signe de malheur, quatre pies signe de bonheur, cinq pies signe de mort, six pies, signe de mariage ». Cette devise transmise par sa grand-mère se retrouve à plusieurs échelons de sa vie. Elle surveille et compte les pies qu'elle peut voir et fait l'association avec ce qui lui arrive. Elle explique également ne pas réussir à se regarder dans un miroir brisé, sans vraiment réussir à expliquer pourquoi, tandis qu'elle reconnaît avoir recours à un rituel superstitieux concernant le sel qui "protège son foyer ». Matilda explique quant à elle avoir été superstitieuse, étant jeune. Notamment : "à 8 ans, je devais monter les marches quatre par quatre ». Elle explique la fonction qu'elle assignait à ce rituel lorsqu'elle était enfant : "Si j'ai fait cet effort-là, euh...ça va bien se passer. D’ailleurs je ne savais même pas quoi, mais c'est ça, ça va bien se passer ». Elle nous confie également avoir une aversion pour le violet. « (...) Parce que je pense que j'avais dû voir un crayon violet par terre en classe et euh... dans l'après-midi il s'est passé un truc, je sais pas, que j'avais trouvé angoissant. Et même aujourd'hui ". Au-delà des couleurs, les chiffres semblent également détenir un pouvoir superstitieux pour cette joueuse : " 8 et 2 j'aime pas trop, mais après je fais des combinaisons où 8 et 2 ça passe".

Ces résultats mettent en évidence la prégnance de la superstition dans la vie quotidienne de ces joueuses françaises. Cela semble être le résultat de l'omniprésence de la superstition dans les familles de Louanne et d'Alice. Matilda quant à elle ne fait pas le lien entre ses rituels et sa famille. Cela semble cohérent puisque comme elle l'a expliqué lors de l'entretien, les rituels sont strictement personnels selon elle.

De plus, pour ces joueuses, la superstition tient logiquement une place importante dans le monde sportif. Toutes trois affirment à demi-mots être des personnes « un peu » superstitieuses. Elles assument donc leur part de superstition tout en gardant une distance à l'égard de ce phénomène qu'elles considèrent comme irrationnel. Alice est consciente que ses superstitions " ne sont pas forcément des sortilèges qui ont un impact direct sur ce que je fais, sur ce que je vais faire, sur ce que je vais réussir à faire ou pas ». Elle évoque être dérangée momentanément lorsqu'elle ne peut pas réaliser ses rituels superstitieux mais ne fait pas d'attributions causales rétrospectives suite à la réalisation, ou non, de ses rituels. Elle considère ses rituels comme "idiots » mais rassurants et affirme qu'ils fluctuent au gré de la vie, des clubs, des saisons, etc.

Louanne définit la superstition comme « une habitude qu'on a, qu'on prend, et qui n'est pas directement liée au travail... ce n'est pas indispensable. Je pense que la superstition n'a rien de logique en fait ». Elle aussi, considère ses superstitions 
comme irrationnelles et les termes qu'elle emploie reflètent cette volonté de prise de distance par rapport à un phénomène qui ne semble pas concorder avec son pragmatisme. L'objectif de la superstition pour cette joueuse est de la faire se sentir " complète »: "Hop c'est bon j'ai tous les trucs, je suis prête pour aller jouer ». Par ailleurs, elle attribue une dimension symbolique forte au fait de parler de la superstition. Elle explique que parler de ses rituels leurs font perdre leurs " pouvoirs » et ce schéma se retrouve dans sa vie quotidienne puisque selon elle parler d'un projet avant sa réalisation "ça porte malheur ». Elle conclut son entretien par une prise de conscience : "plus on en parle, plus on se rend compte qu'on est un peu plus superstitieux».

Matilda quant à elle, s'attache à différencier la superstition du rituel. Elle définit la superstition comme une " névrose »: " pour moi superstition en fait, ça évoque la névrose (...) " un chaos ». Elle va même jusqu'à affirmer que "ça devient clairement handicapant». Selon elle, la superstition ne peut pas être positive, elle résulte d'une angoisse et d'une peur de l'échec. La superstition est incontrôlable car cela la rend " nerveuse » si elle ne peut pas réaliser sa superstition. Elle l'oppose au rituel qu'elle conçoit comme une préparation à ce qui va arriver, à la manière $d^{\prime}$ 'une préparation mentale. Tout se passe comme si la superstition provoquait chez les joueuses françaises un conflit interne. Elles évoquent, si ce n'est assument, leur côté superstitieux mais ne le perçoivent pas forcément comme quelque chose de positif et ont du mal à l'expliquer. Ces trois joueuses présentent de nombreux rituels dont le point commun est qu'ils sont particulièrement liés à la chance ou aux énergies et présentent des " pouvoirs superstitieux ».

Alice porte des " sous-vêtements qui gagnent » et place des barrettes dans ses cheveux $d^{\prime}$ 'une manière spécifique qui correspond à une période de sa vie où elle progressait beaucoup. Elle affirme avoir un numéro " porte bonheur » faisant référence à des dates symboliques pour ses parents tandis qu'elle a inscrit une devise en Roumain sur l'élastique de son short, que lui répète régulièrement son père ( Haut et fort » : faisant référence à la manière de smasher la balle »).

Matilda considère certains nombres comme " porte-bonheurs » : "12, 6, 3, 4, 1 ça va...7 j'aime bien aussi...13 aussi j'aime bien (...) je fais attention à ça aussi pour les chambres d'hôtel ». Elle porte également un bijou porte-bonheur, une chaîne autour de son cou pour laquelle elle accorde un crédit superstitieux et affectif fort, témoignant l'attachement qu'elle porte à sa grand-mère et aux valeurs familiales. Cette joueuse attribue un " pouvoir " particulier à l'action de taper dans la main d'une partenaire. Elle a tendance à taper dans la main d'une partenaire qui a exécuté une bonne action afin de récupérer des ondes positives.

Louanne déclare avoir besoin d'un message de son copain avant un match tandis qu'elle porte une attention particulière aux boucles d'oreilles qu'elle portera. Elle porte toujours deux boucles différentes et pense que chaque boucle apporte une réponse différente, c'est pourquoi elle change en fonction des matchs. Cette joueuse tient à ne pas parler du match avant le match et remercie les ramasseurs de balles lorsqu'elle est sur le point de servir, pensant que «le positif attire le positif ». 
Par ailleurs, ces trois joueuses entretiennent trois rapports singuliers à la religion. Alice s'est détachée de la religiosité familiale et ne se considère pas croyante à I'heure actuelle. Matilda croit en une forme de spiritualité, affirmant croire en des destins, des énergies, qu'elle a du mal à identifier. Elle récite des prières en lien avec sa "lignée », demandant une forme de positivité générale et non une performance quelconque. Louanne est quant à elle devenue croyante, choisissant de se faire baptiser à 13 ans, bien qu'issue d'une famille athée. Elle affirme avoir eu besoin de penser qu'il existe une force supérieure vers laquelle elle pouvait se tourner dans les périodes dites "difficiles». Elle explique qu'elle se recueille parfois (en dehors de l'église) mais ne pratique pas beaucoup et avoue ne pas être complètement d'accord avec l'église, "croyant dans ce qu'elle a envie de croire ».

Enfin, pour Alice et Matilda le groupe sportif possède une influence sur leurs rituels. Alice reconnaît s'inspirer parfois des pratiques superstitieuses des personnes qui l'entourent. Elle essaye les superstitions et voit, à l'usage, si cela fonctionne pour elle. Matilda quant à elle, mâche du chewing-gum et écoute de la musique avant un match et reconnaît avoir mis ces rituels en place par imitation des pratiques de son ancienne équipe.

En résumé, les profils de superstition d'Alice, Matilda et Louanne semblent présenter de grandes similitudes malgré l'hétérogénéité apparente. En effet, ces trois Françaises n'ont semble-t-il pas réellement réussi à se détacher du lien filial en témoigne leur carrière de volleyeuse et l'omniprésence de la famille, régulièrement aux origines de leurs rituels. Deux des trois joueuses françaises semblent d'ailleurs présenter une certaine tendance au conformisme. Par ailleurs, il n'apparaît pas de tendances nettes concernant l'influence de la culture balkanique sur les superstitions d'Alice et de Matilda : la culture française semblant avoir nettement pris l'ascendant lors de la socialisation primaire. Cependant, ces trois joueuses

Figure 3 : Répartition des types de rituels auxquels les joueuses ont recours selon la nationalité

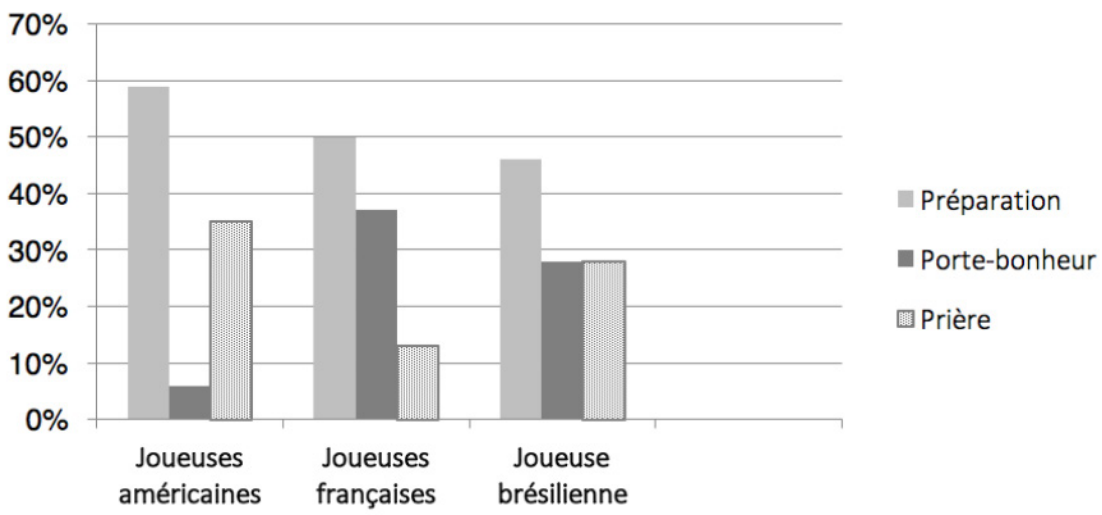


françaises se retrouvent autour du paradoxe difficilement acceptable que semble constituer pour elles leurs rituels : elles considèrent leurs rituels comme "idiots", " ridicules", mais elles ressentent le besoin, voire l'obligation, de les effectuer. Enfin, elles semblent accorder une place centrale à la chance à travers des superstitions variées.

\section{Discussion}

L'importance et la part culturelle des superstitions semblent avérées, même sur une population réduite. En effet, une tendance saillante émerge des résultats des entretiens et du questionnaire, mettant en évidence le lien existant entre la nationalité des joueuses et leur rapport à la superstition. La généralisation n'est ici pas de mise étant donné le caractère exploratoire de ce travail.

\subsection{Superstition, nationalité et socialisation primaire}

Notre première hypothèse apparaît validée puisque la nationalité (1.1) et l'éducation primaire (1.2) des joueuses influencent leur taux de superstition, le type de rituels adoptés, et surtout la manière de les exprimer lors de l'enquête. Des sous-groupes de comportements superstitieux se dégagent au sein de l'équipe : "Françaises », "Américaines » et "Brésilienne ». Le type de superstition ici n'a pas vocation à être extrapolé aux populations mères des joueuses. Au-delà d'un score total de superstition qui diffère selon les nationalités, c'est la différence de nature des rituels qui semble être culturellement signifiante. Les joueuses américaines enquêtées accordent une place importante aux routines et à la religion et déclarent fermement ne pas croire à la chance. La joueuse brésilienne n'oppose pas superstition et religion et semble recourir à des formes variées de rituels, qui justement sont strictement liés à la chance. Enfin, les Françaises accordent un crédit particulier à la chance, aux " énergies » et aux " pouvoirs ». Par ailleurs, elles adoptent toutes les trois des postures différentes face à la religion, mais elles semblent se rassembler autour d'une prise de distance par rapport à son caractère institutionnel.

Les résultats au questionnaire de superstition confirment ces tendances. Cet outil d'analyse quantitative est découpé selon différentes catégories de rituels et nous pouvons constater que la répartition des rituels varie entre les Américaines, les Françaises et la Brésilienne (Figure 3). Nous nous sommes particulièrement intéressés à trois types de rituels apparaissant dans le questionnaire et dans les discours des joueuses : 1) «Porte-bonheur » et la question de la chance, 2) "Préparation » et les routines sportives, 3) «Prière » au regard des religions. Des répartitions différentes sont repérées selon les nationalités des joueuses. Les entretiens confirment les tendances obtenues par les questionnaires, mais surtout les explicitent au regard des valeurs et des croyances des joueuses. Ainsi, la mise en lien des deux outils méthodologiques que sont le questionnaire et les entretiens améliore l'interprétation objective des résultats du questionnaire et de mettre en évidence des éléments communs selon les nationalités. 
Les types de rituels convoqués et exprimés par les joueuses sont en partie dépendants d'une culture nationale et de l'éducation primaire. En effet, malgré une population restreinte, trois figures se distinguent au regard des cultures nationales.

\section{La figure superstitieuse des joueuses américaines}

Les joueuses américaines enquêtées ne croient pas en la chance (seulement 6\% de leurs rituels) par rapport à la préparation et à la prière. Notons qu'une des joueuses américaines qui n'a pas été interviewée a ressentie le besoin de mentionner à la fin de son questionnaire à quel point elle ne croit pas à la chance : " I'm not a superstitious person. I believe superstitious rituals are distracting and only add stress to the athlete because it just creates more things to worry about. I believe talent and training are what brings success, not luck ${ }^{20}$. Cette affirmation semble symptomatique de la culture américaine revendiquée par les joueuses. En effet, Lhérété (2012) montre que l'Amérique est une terre de pionniers qui s'est construite par le bas. Des colons à nos jours, l'initiative individuelle et le travail sont extrêmement valorisés dans cette culture, s'exprimant à travers le "self-mademan ». De plus, l'Amérique est une terre de religion, fondée sur la liberté et sur la diversité des croyances. Les Américains sont solidaires autour de la " religion civile ». Cela se traduit dans les rituels des joueuses américaines qui ont recours à la prière de manière récurrente en comparaison à leurs coéquipières françaises. Enfin, l'esprit d'entreprise, le pragmatisme et le rêve américain se retrouvent dans I'attitude des joueuses américaines à l'égard de la superstition. Elles ne comptent que sur elles-mêmes pour réussir et croient avec ferveur que ce sont le labeur et la volonté qui leur permettront d'atteindre les objectifs qu'elles se sont fixées. Dès lors, accorder une place à la chance dans leur quotidien semble les gêner, voire les effrayer. Cela supposerait qu'elles ne sont plus maîtresses de leurs destins. En somme, les rituels des Américaines semblent être le fruit d'une culture, transmise de manière plus ou moins consciente par la famille, rejetant fermement les superstitions tout en exerçant des routines stéréotypées qui en prennent les contours.

Par ailleurs, un aspect de la socialisation secondaire est notable pour ces joueuses puisque nous avons vu que leur formation à l'université influence leur rapport aux rituels, notamment la relation particulière entretenue avec les routines. Or, le sport universitaire aux Etats-Unis occupe une place singulière. Le haut niveau sportif dans les universités américaines est associé à la réussite sociale et scolaire et il existe un réel engouement (à la fois financier et symbolique) autour de ces pratiques. Dès lors, la relation entretenue avec le coach universitaire est particulière et semble pouvoir influencer plus profondément les pratiques des joueuses.

Nos résultats exploratoires semblent en partie opposés à ceux de Burger et Lynn (2005) qui avaient conclu que les Américains étaient plus superstitieux que les Japonais du fait du crédit qu'ils accordent à la chance. Au vu de nos résultats, concordant avec la littérature à propos de la culture américaine, il semble que les conclusions des travaux de Burger et Lynn soient potentiellement erronés. Or, leurs résultats ont été tirés d'une analyse quantitative, par questionnaire. Une partie de leur questionnaire était destinée à évaluer l'impact de la superstition perçu par les 
joueurs, à travers plusieurs propositions ; "Faire que quelque chose de bien arrive ", "Éviter que quelque chose de mauvais arrive ", "Affecte la performance des joueurs ", "Affecte ce qui arrive à l'équipe ", "Aide à prévenir les blessures » ${ }^{21}$. Cette section du questionnaire semble particulièrement intéressante, cependant elle peut potentiellement, à notre sens, amener les expérimentateurs à de fausses interprétations. En effet, il a été montré dans cette étude que les joueurs américains utilisent la superstition en grande partie pour " faire que quelque chose de bien arrive ». Cependant, lors de la discussion des résultats, les auteurs ont interprété cela comme le fait d'agir pour favoriser la chance. Or, la signification culturelle est sans doute différente, puisque dans nos travaux, les analyses des entretiens avec les Américaines ont montré que les fonctions qu'elles accordent à la superstition ne sont surtout pas liées à la chance puisque dans tous les cas elles la rejettent en bloc (puisqu'elle discrédite à leurs yeux tout le travail sportif effectué en amont de la performance). En effet, les deux joueuses que nous avons interviewées ainsi que la joueuse qui a commenté le questionnaire convergent vers une même opinion. Elles expliquent qu'elles croient plus en dieu, au travail, à leur confiance en elles ou à leurs habiletés comme pouvant influencer leur performance, mentionnant clairement et à plusieurs reprises qu'elles ne croient pas à la chance.

Dès lors, il semble qu'une analyse qualitative complémentaire soit nécessaire pour étudier des comportements superstitieux qui sont personnels et empreints de significations culturelles.

\section{La joueuse brésilienne : une croyance affirmée et syncrétique ?}

Les tendances concernant les types de rituels adoptés par Adriana peuvent également être éclairées par la culture brésilienne. II aurait été intéressant de pouvoir comparer les comportements superstitieux d'au moins deux joueuses d'origine brésilienne, cependant, la composition de l'équipe ne nous l'a pas permis. Pour autant, les rituels auxquels Adriana a recours semblent tout à fait cohérents avec la culture partagée dans son pays. En effet, les rituels de cette joueuse sont relativement nombreux et variés, tout comme les religions et croyances au Brésil sont multiples. D'ailleurs, cette joueuse se revendique catholique et explique que son frère est tourné évangéliste. Soares (2009), dans son ouvrage sur "Les Brésils » introduit un chapitre par une expression populaire qui caractérise le Brésil ; "Terra de todos os santos e de quase todos os pecados " $c^{\prime}$ est à dire "Terre de tous les saints et de presque tous les péchés ». La culture brésilienne s'affirme donc autour de cette religiosité, de cette hétérogénéité et de cette tolérance. Dès lors, il semble logique qu'Adriana n'oppose pas réellement superstition et religion. Ainsi, bien qu'elle admette l'existence d'une différence entre ces deux croyances, $c^{\prime}$ est le fait de " croire » qui est central pour elle. DaMatta livre une description intéressante du "type brésilien » en comparaison au "type américain »: "Je sais que je suis Brésilien et non Nord-Américain parce (...) je suis loyal à mes amis et parce que je ne peux rien refuser à ma famille ; parce que finalement j'ai des relations personnelles qui ne me permettent pas de marcher tout seul dans ce monde comme le font mes amis américains qui ne se voient et n'existent que 
comme des individus» (1984). Adriana semble correspondre à ce "type brésilien » à l'image de ses superstitions. En effet, elle entretient une relation précieuse avec sa mère et celle-ci est bien souvent à l'origine de ses rituels, en témoigne la signification qu'Adriana accorde à la couleur rouge. De plus, cette joueuse n'est pas gênée à l'idée de parler de l'importance de la superstition, de la religion et du crédit qu'elle attribue à la chance dans sa vie. Adriana accorde de l'importance au travail et à la volonté pour atteindre ses objectifs mais elle favorise les relations sociales et la famille pour réussir.

\section{Une figure superstitieuse française ?}

Alice, Matilda et Louanne adoptent une posture relativement similaire à l'égard de la superstition. Elles assument le fait d'être superstitieuses mais peinent à accepter ce statut qui semble générer un conflit interne chez elles. II est difficile pour ces joueuses d'expliquer comment un phénomène aussi peu rationnel à leurs yeux se révèle être un besoin, voire une obligation. Dès lors, elles affirment leur superstition de manière étouffée, minimale : " $C^{\prime}$ est ridicule je sais », " c'est idiot », " je suis un peu superstitieuse ». Cette posture apparaît symptomatique de la culture française puisqu'elle est constituée du jugement permanent d'autrui, organisé autour de ce que d'Iribarne (1993) nomme dans le domaine de I'entreprise : " la logique de I'honneur ». Ainsi, la distinction entre ce qui est noble et ce qui ne l'est pas, ce qui est honorable ou non fait sens dans la culture française. Selon l'auteur, ce code de I'honneur subsiste depuis des siècles en témoigne la distinction du pur et de l'impur au Moyen âge. Ainsi, concernant la superstition, on peut supposer que les trois joueuses françaises considèrent cette pratique-croyance comme "nonnoble"... sans être ignoble. Dès lors, ce conflit entre leur culture et leurs pratiques superstitieuses les amènent à adopter une posture distante à l'égard de leurs superstitions. Ainsi, bien que toutes trois assument leur statut de superstitieuses, Matilda assimile la superstition au " chaos », Alice dénigre ses rituels et son comportement à leur égard tout comme Louanne qui adopte parfois une attitude fataliste face à ses pratiques ("Voilà c'est bête mais c'est comme ça »).

Par ailleurs, Alice, Matilda et Louanne expliquent que c'est la ferveur de leur croyance en les pouvoirs d'un rituel qui les amènent à user de telles ou telles superstitions. Dès lors, bien qu'elles avouent établir parfois le lien entre une performance et leurs rituels, cette dimension reste secondaire.

Cette posture est spécifique au sous-groupe des Françaises. L'analyse de mots clés se révèle particulièrement intéressante pour ces joueuses qui associent les rituels aux " pouvoir ", aux " énergies ", à la " chance ", au " malheur » ou encore à des "forces ». Ces différents termes réfèrent à la magie et semblent particulièrement éloignés de la définition de la rationalité. Il est difficile de tirer des conclusions quant à l'emploi de ces termes, cependant une des explications pourrait encore une fois être culturelle. En effet, Baudry $(2004,4)$ explique que, contrairement aux Américains qui interagissent avec la réalité à travers les impératifs tels que «Go » ou encore « Have fun » qui supposent l'obligation de l'action immédiate ; les Français ont tendance, à l'image de la caverne de Platon, à « théoriser la réalité » qui est laissée à distance. 
De plus, la culture française s'est largement laïcisée et l'institution religieuse (catholique) a vu son influence sur la population française et ses pratiques décroître de manière significative ces dernières décennies. Cependant, au moment de l'explicitation par entretien, nous avons été intrigués par le rapport qu'Alice, Matilda et Louanne entretiennent avec la religion. En effet, ces trois joueuses constituent trois postures qui ne sont pas strictement laïques, comme nous aurions pu le supposer, à l'égard de ce type de croyance. Leurs relations à la religion sont relativement hétérogènes, mais il semble tout de même exister des points communs. Alice et Matilda ne s'identifient à aucune institution : Alice affirme ne croire en rien tandis que Matilda croit en des destins, des énergies et des forces supérieures qui lui sont personnelles et qu'elle peine à expliciter. Par ailleurs, Louanne a fait le choix de se tourner vers la religion au sens institutionnel du terme choisissant d'effectuer la démarche rituelle et symbolique du baptême à l'âge de 13 ans. Ces trois types de postures semblent pouvoir être explicités et éclairés par les caractéristiques de la culture française. En effet, Alice s'est détachée d'une pratique religieuse empreinte de la culture d'Europe de l'Est pour se tourner vers la laïcité qui caractérise la culture française. Matilda, quant à elle, affirme avoir de réelles croyances et effectuer des prières exclusivement associées à la pratique sportive et n'étant pas associée à une quelconque institution. Dès lors, cela semble constituer un type de croyance à part entière que l'on pourrait qualifier de spirituel plutôt que religieux. Par ailleurs, Louanne se considère comme croyante mais ne s'identifie pas pour autant à I'institution en tant que telle. Sa croyance religieuse réside dans le recueillement libéré des contraintes de l'église. Cela semble comme Matilda se rapprocher d'une forme de spiritualité. Cependant, Louanne a tout de même été baptisée, c'est donc une démarche que I'on ne peut ignorer. Toutefois, il apparaît que les trois joueuses françaises, en comparaison aux Américaines et à la Brésilienne n'accordent pas un rôle central et organisateur à la religion dans leur vie comme dans leurs rituels.

Nous avons mis en évidence quelques éléments d'un « profil superstitieux Français » à travers le crédit accordé à la chance et l'emprise de la socialisation primaire et de la famille. Cependant, il est difficile de définir avec précision à quel point la culture est-européenne de Matilda et Alice influence leurs pratiques. Par exemple, Alice semble se dédouaner de ses rituels, adoptant un comportement presque passif à leur égard et expliquant de manière fataliste comment elle semblait destinée à être superstitieuse au vu de sa culture est-européenne. Le questionnaire révèle que les deux joueuses françaises d'origines est-européenne présentent des scores de superstition supérieurs à celui de Louanne. Cependant, si la superstition et la religion semblent faire parties intégrantes de la culture du pays d'origine d'Alice, cette tendance ne se retrouve pas dans la famille de Matilda.

Cette première partie de notre discussion confirme donc l'hypothèse selon laquelle la socialisation primaire, à travers la famille et la culture nationale, est au centre des rituels superstitieux adoptés par les joueuses. II en découle donc des comportements logiquement différents selon les nationalités des sujets. Par ailleurs, I'influence notable d'une socialisation secondaire sur les rituels des Américaines reste ancrée dans la culture nationale. 


\subsection{Superstition, cohésion, normes et conformisme}

La seconde hypothèse concernant une potentielle influence de la cohésion (2.1), des normes du groupe ou du leader (2.2) sur les comportements superstitieux des joueuses ne peut être validée. À partir des données obtenues, I'influence du groupe sportif en tant que socialisation secondaire ne semble avoir qu'une influence minime. Il faut noter que la population d'enquête est particulière de ce point de vue puisqu'un renouvellement de l'effectif venait de se produire dans cette équipe professionnelle. En ce sens, les normes implicites qui unissent la totalité des joueuses autour des mêmes rituels, sont des normes légitimées par l'ensemble de la communauté du volleyball et du sport de haut niveau en général. Dès lors, même les leaders du groupe n'ont pas d'influence significative sur les comportements superstitieux de leurs coéquipières. Cela peut aussi s'expliquer par la faible cohésion de cette équipe, caractérisée par une division nette entre un sous-groupe "Américaines » et les autres joueuses (Figure 2 et Figure 3).

Alice et Matilda semblent être sujettes à un certain " conformisme superstitieux ", en raison probablement de leur jeune âge ou de leur manque d'expérience dans le sport de haut niveau. On peut aussi penser que cette tendance est plus logiquement observée chez des joueuses françaises, moins indépendantes et individualistes que les joueuses américaines. Enfin, puisque cette tendance au conformisme se retrouve chez deux joueuses françaises d'origine Est-Européenne, peut être cette tendance à l'imitation traduit une volonté d'intégration largement inconsciente.

\subsection{Limites et propositions}

Cette étude conduit logiquement à discuter la pertinence du questionnaire des rituels de superstition. Nous avons eu recours à la version de Bleak et Frederick (1998) modifiée par Flanagan (2002). Partant d'un point de vue relativement critique de cet outil, il ne s'en est pas moins révélé intéressant pour mettre en évidence de manière générale à quel point des personnes sont "superstitieuses ». De plus, l'exploitation que nous en avons faite à travers la comparaison des types de rituels adoptés selon les nationalités, prouve que certains items sont révélateurs. En effet, nous avons particulièrement exploité les items "Prière ", "Préparation » et "Porte-bonheur», pour révéler des tendances-figures types. Cependant, des lacunes justifient notamment un travail d'entretien complémentaire et approfondi. En effet, la partie ajoutée par Flanagan « Rituels de superstition Partie 2 » propose des rituels largement mentionnés par les joueuses, qui mériteraient d'être intégré à la classification générale par items. Cela faciliterait l'analyse du questionnaire et ajouterait une cohérence d'ensemble. Par ailleurs, Flanagan évoque dans la partie discussion de son étude que les participants semblent avoir du mal à distinguer les rituels superstitieux des routines. Cependant, il semble que ce soit certaines questions du questionnaire lui-même qui puissent prêter à confusion. En effet, des questions, notamment au sein des items "Préparation », " Match » et " Rituels d'équipe » mériteraient d'être reformulées ou supprimées pour ne pas biaiser les résultats. Certaines formulations font clairement référence à des routines de préperformance, voire d'échauffement, ou à des normes usuelles du monde sportif 
en général, et non à de la superstition ("Vous vous échauffez pour le match en utilisant la même routine? » ou encore " À quelle fréquence effectuez-vous un cri de guerre ou chant avant votre match ? »). Notons que les rituels les plus mentionnés par les joueuses de cette équipe se rapportent logiquement aux items : "Préparation», "Match » et "Rituels d'équipe ». Ainsi, ce genre de questions est incohérent par rapport à la volonté du questionnaire de bien différencier les routines des superstitions. D'ailleurs, certaines joueuses ont régulièrement commenté les items du questionnaire en mentionnant si elles considéraient le rituel comme de la superstition ou non.

Malgré tout, les routines et même la religion peuvent révéler un certain rapport à la superstition et parfois présenter un caractère superstitieux, permettant d'alimenter la réflexion. Mais cette explicitation est uniquement rendue possible par une analyse qualitative complémentaire, notamment par entretien récurrent et étendu à une population plus conséquente. À cette condition, il semble intéressant voire indispensable d'envisager la superstition à travers un système global de valeurs et de croyances. Nous avons choisi dans cette étude d'observer le phénomène superstitieux sans nécessairement l'opposer à la religion ou aux routines comme $c^{\prime}$ est le cas dans les questionnaires. Notre réflexion s'est alors organisée autour de I'interdépendance qui lie ces pratiques magico-religieuses. Cela permet la prise en compte des différentes dimensions et de la complexité qui caractérise la superstition, au même titre que toutes les pratiques humaines. Dès lors, la superstition n'est pas seulement « croire », c'est aussi " aimer faire » ou " aimer répéter », c'est « avoir l'habitude » ou bien " devoir»; en témoigne les termes employés par les joueuses lors des entretiens. La connotation irrationnelle de la superstition que nous évoquions en introduction pousse les individus à euphémiser leurs propos lorsqu'ils évoquent cette pratique. Dès lors, la superstition peut renvoyer à la fois à des valeurs, des routines, des modes vie ou bien des habitudes dans les discours des joueuses.

Une analyse qualitative approfondie permettrait de déceler cette complexité et dans le cadre d'une analyse strictement quantitative, se limitant au questionnaire, peut être certaines questions devraient être reformulées pour que la frontière entre superstition, religion et routine apparaisse plus nette, à défaut de pouvoir l'analyser et l'interpréter par entretien. Pour cela, des notions telles que la dépendance, la fatalité ou l'implication de la chance dans les rituels semblent des éléments pertinents pour caractériser uniquement la superstition. Finalement, cette étude exploratoire soulève des points intéressants, notamment quant à une méthodologie à adopter pour étudier les rituels superstitieux. Pour les travaux de recherche futurs, il semble incontournable de coupler analyses quantitatives et qualitatives. En effet, il apparaît que certains rituels sont relativement singuliers et que, plus qu'un taux de superstition, ce sont les types de rituels utilisés qui semblent constituer des objets de recherche signifiants. Par ailleurs, le questionnaire semble demeurer un outil indispensable et mériterait quelques modifications. Il serait notamment intéressant de faire une synthèse des aspects positifs des questionnaires de Bleak et Frederick (1998) et de Burger et Lynn (2005). La 
question ouverte ajoutée par Flanagan à la version du questionnaire de superstition constitue aussi un élément incontournable.

Concernant l'analyse par entretien, il serait nécessaire d'effectuer ce travail de recherche à plus grande échelle puisque nos analyses à propos du lien entre superstition et nationalité se basent sur de faibles effectifs. Dès lors, bien que nous ayons observé des tendances relativement nettes, la prudence est de mise à l'égard de ces résultats afin d'éviter des surinterprétations. De plus, comme le souligne Flanagan dans la conclusion de son étude, la superstition est quelque chose de relativement personnelle. Les joueuses construisent leurs rituels à travers leurs valeurs, leurs représentations et leurs croyances de manière individuelle, si ce n'est singulière. Ainsi, bien que la culture soit en partie à l'origine des rituels adoptés, il serait intéressant de préciser l'influence de la personnalité des joueuses, l'originalité de leur trajectoire sportive (avec ou sans blessure ou bien suivant une relation apaisée ou conflictuelle avec l'entraineur et/ou le reste de l'équipe par exemple) sur leur rapport à la superstition. Il a notamment été montré que l'anxiété favorise les comportements superstitieux (Bleak \& Frederick, 1998).

\section{Conclusion}

Cette étude exploratoire précise une influence notable de la socialisation primaire sur les comportements superstitieux dans le monde sportif professionnel féminin. L'éducation et les valeurs transmises par la famille ainsi qu'une culture nationale incorporée semblent être à l'origine du rapport que chaque sportive entretient avec la superstition. Dès lors, nous avons souligné l'existence de différences nationales quant aux types de rituels superstitieux adoptés par les joueuses. Le travail d'analyse qualitative des rituels a permis de différencier trois figures ou profils superstitieux types qui correspondent à trois nationalités : Française, Américaine et Brésilienne. Il apparaît que la place accordée à la chance, aux routines et à la religion, par rapport aux autres rituels est significative d'un rapport spécifique à la superstition.

Par ailleurs, l'analyse des entretiens révèle que les rituels possèdent des significations plurielles et que classer/ séparer les systèmes de croyances pour les étudier, réduit la complexité de la réalité sportive. Il apparaît donc essentiel d'appréhender les rituels comme des phénomènes dynamiques et mouvants à envisager aux côtés de la religion, des valeurs, de l'éducation ou encore des habitudes, ceci afin d'éviter des interprétations hâtives (Burger, Lynn, 2005).

Finalement, cette étude exploratoire prolonge la littérature, mettant en évidence à quel point la superstition est un phénomène répandu chez les sportifs, ici des sportives, notamment de haut niveau. Les analyses à la fois quantitatives et qualitatives des rituels superstitieux menées offrent une contribution originale aux champs de la psychologie et de la sociologie du sport et permettent de dépasser les carcans actuels des travaux sur la superstition, qu'ils soient méthodologiques ou disciplinaires. De récentes études vont dans ce sens, tendant à considérer la complexité du phénomène superstitieux. Obadia évoque notamment le fait que " la superstition n'est pas qu'une affaire de culture et de psychologie, fut-elle sociale ou indivi- 
duelle : elle est aussi ancrée dans une histoire travaillée par des forces idéologiques et politiques au sein desquelles elle a été instrumentalisée à des fins de pouvoir » (Obadia, 2016, 5).

\section{Notes}

1. "Etude réalisée les 21 au 22 octobre 2014 auprès de 1001 personnes constituant un échantillon représentatif de la population française âgée de 18 ans et plus, interrogé sur internet selon la méthode quotas en fonction du sexe, de l'âge, de la profession, de la région et de la catégorie d'agglomération".http://www.lci.fr/conso-argent/la-recette-du-bonheurbeaucoup-de-volonte-et-un-peu-de-superstition-1562803.html. Consultée le 31/08/2016.

2. Cités par Flanagan, 2013, p. 11.

3. Superstitions associées au terme plus général de "magie" dans ces travaux.

4. Cités par Flanagan, 2013, p. 5.

5. Cités par Flanagan, 2013, p. 7.

6. Cité par Billing, 2014, p. 1.

7. Les superstitions étant parfois présentées d'une manière plus ou moins condescendantes comme des éléments de la croyance naturelle populaire (Saint Martin, 2015) ou la culture magique des campagnes (Boutry, 2011 ; Didier, 2011).

8. Le biais mémoriel intervient ici : des entretiens répétés (après six mois, un an, deux ans) pourraient éventuellement contrôler ce biais.

9. Traduction par H. Lesage et P.H. Maucorps, 1955.

10. Traduction : "Je ne suis pas vraiment... genre... superstitieuse. II y a genre quelques trucs... Je pense que ... Je ne sais même pas si on peut dire que c'est de la superstition ou si ce sont juste des routines. Euh mais oui... je ne sais pas »(rires)

11. Traduction : "Ouais, je dois toujours genre mettre ma chaussette droite en premier et ensuite ma chaussette gauche puis ma genouillère droite puis ma genouillère gauche et ensuite ma chaussure droite puis ma chaussure gauche ».

12. Traduction : " J'en ai entendu parler, je connais des gens qui sont vraiment superstitieux euh....mon frère je pense qu'il l'est probablement plus... assez superstitieux (...) Mais ... pour moi... je ne crois pas que je doive ... genre, si je ne touche pas ton bras droit avant de jouer alors je vais mal jouer (...) Je crois plus en ma confiance et mes habiletés à jouer. Donc j'ai des routines, j'adore les routines. Mais ce n'est pas genre « Oh je n'ai pas fait ça aujourd'hui donc tout est fichu»

13. Traduction : «Je pense que les routines c'est la santé (...) Euh... je veux dire, tout le monde doit faire des choses pour conserver le moment. Mais je pense qu'avoir un rituel ... Enfin, je pense que quand tu as des enfants c'est important pour eux d'avoir une routine tous les matins juste pour qu'ils puissent, pour que nous puissions vivre au même rythme. Donc je pense que c'est important. 
14. Traduction : «Euh... Je pense que quand j'étais une petite fille (...) Je pense que mes parents ont en quelque sorte commencé ça, genre "Kate si tu manges bien tu te sentiras mieux et tu auras plus d'énergie pour le match » (...) Donc je pense que maintenant que je suis plus âgée et que c'est en quelque sorte imprégné c'est beaucoup plus culturel ».

15. Traduction : "Elle est vraiment du genre « Il faut avoir une routine », tous les rituels genre «tu dois faire tous ces trucs. Oui elle est vraiment... je pense que c'est la raison pour laquelle je le suis".

16. Traduction : «Je pense que c'est plus pour, genre, favoriser la chance. Dans le sens où $c^{\prime}$ est plus pour apporter des ondes ou des bonnes... enfin je ne pense pas que c'est nécessairement pour éviter quelque chose ».

17. Traduction : «Euh... je pense que ... je pense que je suis plus du côté de la religion. Parce que je prie avant les matchs et je pense que je crois plus en ça qu'à la superstition ».

18. Traduction : "Euh mais nous avons tous grandi en tant que Chrétiens, à l'église, donc je pense que nous croyons plus en dieu que nous ne croyons à la chance ou à la superstition ».

19. Elle fait précisément référence aux habitants de son pays d'origine, que l'on a souhaité garder anonyme dans cette étude.

20. Traduction : "Je ne suis pas une personne superstitieuse. Je pense que les rituels superstitieux sont perturbants et n'ajoutent que du stress à l'athlète car cela ne fait qu'ajouter des choses à propos desquelles s'inquiéter. Je crois que le talent et l'entrainement sont ce qui apporte le succès, pas la chance ».

21. Traduction de I'anglais.

\section{Bibliographie}

- Aitken, B. W. W., (1993)."The emergence of born-again sport", In: Prebish, C.S (ed.), Religion and sport: the meeting of sacred and profane, Westport, Connecticut, Greenwood Press, 197-214.

- Askevis-Leherpeux, F. (1978). Les corrélats de la superstition. Remarques critiques sur quelques travaux anglo-saxons. Archives de Sciences Sociales Des Religions, 165-176.

- Askevis-Leherpeux, F. (1990). Croyance au surnaturel et instruction. Communications, 52(1), 161-174. http://doi.org/10.3406/comm.1990.1789

- Baudry, P. (2004). À la découverte des différences entre Français et Américains. Le Journal de L'école de Paris Du Management, 48(4), 7-7.

- Berger, P. L., Luckmann, T., \& Zifonun, D. (2002). The social construction of reality. na. Retrieved from http://www.academia.edu/download/40517434/_Peter_L._Berger_Thomas_ Luckmann_The_Social_ConsBookFi.org_1.pdf

- Billing, L. E. (2014). Pre-performance routines among club volleyball players: the relationship between routines and Accuracy in serving. UNIVERSITY OF MINNESOTA. Retrieved from http://conservancy.umn.edu/handle/11299/165423

- Blanchet, A., \& Gotman, A. (2010). L'entretien: L'enquête et ses méthodes (2e édition). Paris: Armand Colin. 
- Bleak, J. L., \& Frederick, C. M. (1998). Superstitious behavior in sport: Levels of effectiveness and determinants of use in three collegiate sports. Journal of Sport Behavior, 21(1), 1-15.

- Bonardel, F. (2005). L'irrationnel (Édition : 2e éd). Paris: Presses Universitaires de France - PUF.

- Boutry, Ph., (2011). "Superstition, religion et raison : le romantisme français face à la culture magique des campagnes ", in: Les Religions au XIXe siècle, Sophie Guermès et Bertrand Marchal (dir.), http://etudes-romantiques.ishlyon.cnrs.fr/religions.html.

- Breton, J.-C. (2000). Comprendre la superstition. Théologiques, 8(1), 9. http://doi. org/10.7202/005002ar

- Buhrmann, H. G., \& Zaugg, M. K. (1981). Superstitions among basketball players: An investigation of various forms of superstitious beliefs and behavior among competitive basketballers at the junior high school to university level. Journal of Sport Behavior, 4(4), 163-174.

- Buhrmann, H. G., \& Zaugg, M. K. (1983). Religion and superstition in the sport of basketball. Journal of Sport Behavior, 6(3), 146-157.

- Burger, J. M., \& Lynn, A. L. (2005). Superstitious Behavior Among American and Japanese Professional Baseball Players. Basic and Applied Social Psychology, 27(1), 71-76. http://doi. org/10.1207/s15324834basp2701_7

- Damisch, L., Stoberock, B., \& Mussweiler, T. (2010). Keep Your Fingers Crossed!: How Superstition Improves Performance. Psychological Science, 21(7), 1014-1020. http://doi. org/10.1177/0956797610372631

- Didier, B., (2011). "Le Diable et le bon Dieu aux champs. La religion des campagnes dans quelques textes de George Sand », in: Les Religions au XIXe siècle, Sophie Guermès et Bertrand Marchal (dir.), http://etudes-romantiques.ishlyon.cnrs.fr/religions.html.

- Dugas, É., Vieille Marchiset, G., \& Gibout, C. (2013). Éditorial. Le sport : de I'incertitude à I'incertain. Staps, 99(1), 7. http://doi.org/10.3917/sta.099.0007

- Flanagan. (2013). Superstitious ritual in sport and the competitive anxiety response in elite and non-elite athletes. Retrieved from http://esource.dbs.ie/handle/10788/1599

- Gardair, E. (2013). Échelle d'inquiétude, échelle de croyances religieuses et superstitieuses : quels liens? Bulletin de psychologie, Numéro 524(2), 135-148.

- Gardair, E. (2015, juillet). « Croyances religieuses, rites et superstition répondent-ils à un besoin de contrôle? » [text]. Retrieved August 31, 2016, from http://lodel.irevues.inist.fr/ cahierspsychologiepolitique/index.php?id=3129

- Gollier, C., (2005). «Les déterminants socio-économiques des comportements face aux risques. Commentaire », Revue économique, 56(2), 417-421. DOI 10.3917/reco.562.0417

- Hamerman, E., \& Johar, G. (2009). Can Switching Brands Help Your Favorite Team Win the Big Game? NA - Advances in Consumer Research Volume 36. Retrieved from http:// acrwebsite.org/volumes/14328/volumes/v36/NA-36

- Higgs, Robert J. (2015). God In The Stadium: Sports and Religion in America, Lexington, University Press of Kentucky.

- Iribarne, P. d'. (1993). La logique de l'honneur - Gestion des entreprises et traditions nationales. Paris: Seuil.

- Lahire, B. (2004). La culture des individus. Dissonances culturelles et distinction de soi, Paris, La Découverte, 731. 
- Lamine, A. (2013). Croire et douter, une perspective sociologique et pragmatique. Nouvelle revue de psychosociologie, 16(2), 37. http://doi.org/10.3917/nrp.016.0037

- Lapointe, G. (2000). Superstition et divination. Théologiques, 8(1), 5. http://doi. org/10.7202/005013ar

- Lhérété, H. (2012). De la pensée en Amérique. Sciences Humaines, (Hors-série n¹7).

- Maranise, A. M., \& others. (2013). Superstition \& religious ritual: An examination of their effects and utilization in sport. Sport Psychologist, 27(1), 83-91.

- P.-H, M. (1955). Moreno (J.L.). «Fondements de la sociométrie». Traduit d'après la seconde édition américaine (Who Shall Survive?) par H. Lesage et P.-H. Maucorps. Revue Française de Science Politique, 5(3), 641-646.

- Obadia, L. (2016). Les « superstitions » à I'épreuve de la modernité: un retour en grâce? Social Compass, 0037768616663985.

- Qribi, A. (2010). Socialisation et identité. L'apport de Berger et Luckmann à travers « la construction sociale de la réalité ». Bulletin de psychologie, Numéro 506(2), 133. http://doi. org/10.3917/bupsy.506.0133

- Rocher, G. (1992). Culture, civilisation et idéologie. Introduction à la sociologie générale.

- Rudski, J. (2001a). Competition, superstition and the illusion of control. Current Psychology, 20(1), 68-84.

- Rudski, J. (2001b). Competition, superstition and the illusion of control. Current Psychology, 20(1), 68-84.

- Rudski, J. (2004a). The illusion of control, superstitious belief, and optimism. Current Psychology, 22(4), 306-315.

- Rudski, J. (2004b). The illusion of control, superstitious belief, and optimism. Current Psychology, 22(4), 306-315.

- Saint-Martin, I. (2015). Approches du merveilleux dans la culture catholique du xixe siècle. Romantisme, (170), 23-34.

- Soares, E. (2009). Le butinage religieux: pratiques et pratiquants au Brésil. KARTHALA Editions.

- Torgler, B. (2007). Determinants of superstition. The Journal of Socio-Economics, 36(5), 713-733. http://doi.org/10.1016/j.socec.2007.01.007

- Tremblay, S. (2000). Magie, superstition et tradition chrétienne: Pistes d'interprétation théologique. Retrieved from http://id.erudit.org/iderudit/005029ar

- Wiseman, R., \& Watt, C. (2004). Measuring superstitious belief: why lucky charms matter. Personality and Individual Differences, 37(8), 1533-1541. http://doi.org/10.1016/j. paid.2004.02.009 